\title{
Evaluation of 'Infant at Risk' Registers
}

\author{
E. G. KNOX and D. F. MAHON \\ From the Health Services Research Centre, University of Birmingham; and the City of Birmingham Health Department
}

\begin{abstract}
Knox, E. G., and Mahon, D. F. (1970). Archives of Disease in Childhood, 45, 634. An evaluation of 'infant at risk' registers. The operational effectiveness of Infant At Risk Registers was examined using record linkage techniques. Two operations were carried out: (a) the linkage of the 1965 Birmingham Observation Register with the 1968 file of 'Defective Children' as notified to the Education Department; and (b) the file of maternity data for the whole of Birmingham in 1956, linked with the list of children receiving special education in 1968.

Positive associations were found between assessment of risk in the Observation Register and subsequent defects as notified to the Education Department at age 3; and between assessment of risk made on the basis of the maternity data and the likelihood of requiring special education at age 13 . The main predictors were low birthweight, traumatic delivery, and the indices of social underprivilege.

However, none of these determinants were sufficient to justify the continuation of selective At Risk Registers whose purpose is defined in terms of prediction. They should be withdrawn or should be redesigned to the different purposes of registering the known handicapped, and extending developmental surveillance to all children, rather than concentrating it upon a few.
\end{abstract}

The strategy of an 'Infant At Risk' Register is to identify a group of infants who warrant an effective concentration of limited health surveillance resources. Its further objective is the early delivery of medical and other care to those who need it.

The tactics, however, are defined less exactly, and it is seldom stated what these children are at risk of, or what is expected from their early ascertainment. It is not often recognized that 'at risk' registration schemes should include the means of their own evaluation, and these means are not often provided. In addition there has often been confusion between registration of risk for the purpose of surveillance, and the registration of evident abnormality for purposes of observation and assessment. Many schemes combine both functions in a single complex operation and this has made it especially difficult to evaluate the separate parts. It is possible as a result of this that the main usefulness of a particular register could be in terms other than those of its declared objectives, and a useful scheme could be terminated because it was evaluated in terms of inappropriate criteria.

The present study explores the situation by establishing linkages between registers permitting

Received 27 February 1970. an early prediction of risk, and registers recording the later existence of handicap. The chief purpose of the study is an evaluation of the operational effectiveness of predictions made at about the time of birth.

Two separate operations are undertaken. The first is based upon an 'Observation Register' set up in Birmingham in 1965, linked with a 'Defective Child' register used to notify the Education Department of potential problems at 3 to 4 years old. The second is based upon the maternity record and associated social data of all children born in the City of Birmingham, and the Education Authority's register of handicapped children requiring special school facilities.

\section{Materials and Methods}

(A) First analysis. The Birmingham Observation Register was established in January 1965 and maintained centrally for two years; since then it has been dispersed. The central records were held on cards holding written identities and clinical notes, while coded handicap and registration details were punched round the edges.

The 'Defective Children' file consisted of filing card copies of notices from the Health Department to the Education Department that an educational problem might be expected.

In order that the ascertainment of defective children 
should be as complete as possible, notices up to the end of 1968 were matched with Observation Register records referring to births in January and February 1965. The usual age at notification was 3 years and the notices therefore referred to children who at the time of the study had reached a minimum age of 3 years and 10 months.

(B) Second analysis. The Birmingham Birth Register consists of a file of all maternities, with obstetric and social data, held on 80 column punch cards and computer magnetic tape. The magnetic tape records go back as far as 1950. The Education Department holds a file of children receiving special education and this consists both of case folders and a set of index cards. This is a 'live' file and children who have not started or who have left school, or who have left the City, are more difficult to trace. In addition, children with such serious mental handicap as to be ineducable are not included; they are listed elsewhere, in the Mental Health section of the Health Department.

Preliminary studies of the completeness and quality of the maternity information indicated that the births of 1956 linked with the current (1969) register of handicapped children would be the best set for a linkage operation of the kind we had in mind. By age 12 to 13 almost all handicaps have been ascertained. The possibility of adding ineducable children was considered, but these cases are less relevant to the object of concentrating useful surveillance upon a limited group of children because the very severe mental handicaps are not generally amenable to early treatment, and in any case usually present spontaneously.

The Education Department handicap file was scanned and identity data (names, date of birth) and details of handicap type were extracted for all children with dates of birth in 1956. The data were transferred to punch cards and a computer linkage carried out between the 652 records so assembled and the magnetic tape file of births for that year.

\section{Results}

(A) First analysis. There were 3,480 live births in Birmingham in January and February 1965 and $1038(29.8 \%)$ were entered to the 'observation Register'. By the end of 1968, 240 children born in these months $(7.0 \%)$ had been notified as 'defective' and most of them (214) were also found in the Observation Register. At first this suggests an efficient predictive mechanism but a more detailed examination showed that it was not as efficient as it seemed.

First, there was a large group of infants (77) who entered both registers because of a defect actually evident at birth; it was ascertained rather than predicted. Some were permanently disabled ( 9 mongols, 5 with spina bifida, 1 with microcephaly, etc.) and some recovered with treatment ( 5 with cleft of lip and palate, 17 with talipes, 4 with dis- located hips etc.). Others were registered because of doubts which later proved unjustified. For many in the last two groups the purpose of notification was to initiate a final review rather than to specify a defect.

Thus, entry to the Observation Register did not necessarily imply a prediction and entry to the Defective Child list did not necessarily mean that a defect was present.

A second large group of infants (80) were entered to the Observation Register as true 'predictions', but to the Defect Register either because a very minor defect had been recorded (13 with umbilical hernia, 13 with naevi, 10 slow feeders, 3 with wide fontanelles) or because of a more substantial problem which had in fact been resolved (e.g. innocent cardiac murmurs, inguinal hernias which had been operated upon, late walking with subsequent normal development). The second entry may never have been made if there were not already in existence a card on which to make it. Notification of defect was essentially a clerical operation for the transfer of any recorded information from one department to another and not a medical assessment based upon a clinical review.

A third main ambiguity arose from combining the documentation of prediction with that of observa-

\section{TABLE I}

Neonatal Prediction of Abnormality which was later confirmed

\begin{tabular}{|c|c|}
\hline Case No. & Description \\
\hline 1 & $\begin{array}{l}\text { Ocular albinism, partially sighted, predicted on basis } \\
\text { of family history }\end{array}$ \\
\hline 2 & $\begin{array}{l}\text { Probable cerebral palsy with hypertonicity of arms and } \\
\text { and legs, predicted on basis of low birthweight and } \\
\text { difficult delivery }\end{array}$ \\
\hline 3 & $\begin{array}{l}\text { Epilepsy, mental retardation, and weak right arm } \\
\text { predicted on basis of difficult labour }\end{array}$ \\
\hline 4 & $\begin{array}{l}\text { Blind and mentally retarded, predicted on basis of } \\
\text { evident birth injury and asphyxia. }\end{array}$ \\
\hline 5 & $\begin{array}{l}\text { Mental subnormality plus spastic right hand predicted } \\
\text { on basis of premature and difficult labour }\end{array}$ \\
\hline 6 & $\begin{array}{l}\text { Floppy baby with mental retardation predicted on } \\
\text { basis of birth injury }\end{array}$ \\
\hline 7 & $\begin{array}{l}\text { Mentally defective baby, initially thought to be deaf, } \\
\text { predicted on basis of low birthweight and difficult } \\
\text { labour }\end{array}$ \\
\hline 8 & Retarded baby predicted on basis of short gestation \\
\hline 9 & $\begin{array}{l}\text { Retarded baby predicted on basis of maternal mental } \\
\text { illness and separation }\end{array}$ \\
\hline 10 & $\begin{array}{l}\text { Blind and quadraplegic predicted on basis of pre- } \\
\text { mature delivery }\end{array}$ \\
\hline 11 & $\begin{array}{l}\text { Spastic cerebral palsy predicted on basis of haemolytic } \\
\text { disease, premature delivery, and difficult labour }\end{array}$ \\
\hline 12 & $\begin{array}{l}\text { Retarded or possibly deaf child predicted on basis of } \\
\text { low birthweight and early uterine bleeding }\end{array}$ \\
\hline 13 & $\begin{array}{l}\text { Deaf child predicted on basis of maternal rubella in } \\
\text { first trimester }\end{array}$ \\
\hline 14 & $\begin{array}{l}\text { Mental retardation predicted on basis of maternal } \\
\text { rubella in first trimester }\end{array}$ \\
\hline
\end{tabular}


tion, with the result that children who became ill at later ages were at the same time entered in the Observation Register, resulting in effect in a retrospective prediction. At least 23 were registered in this manner, but there may have been others, because the register did not record systematically the date of entry. Another group of 11 were predicted 'at risk' and later became ill but demonstrated no clear connexion between the basis of prediction and the abnormality which eventually appeared. They included a child at risk from maternal hyperemesis who later developed eczema, a child at risk from maternal mental disorder who developed fragilitas ossium; a child with birth injury who later developed coeliac disease; another with difficult labour who later developed tuberculosis .... and so on. In a further 9, prediction was followed by an unresolved doubt rather than a definite abnormality.

These exclusions finally reduced the 214 children on both registers to a small group of 14 in whom there seemed to have been a reasonable connected prediction of an abnormality not immediately evident in the neonatal period. They are listed in Table I.

Besides the 14 predicted cases of substantial motor and mental defects, there were another 17 similar cases which either had not been entered in the Observation Register at all, or which were entered 'retrospectively'. Thus, within the limits of interpretation of the data there appeared altogether to be 31 ascertained disorders of this kind, of which 14 would properly be inside an 'At Risk' Register and 17 properly outside it. If we were to exclude from the existing Observation Register those children with malformations evident at birth and those with retrospective registration, we can see that we have located almost half such defects within a little more than a quarter of the population. Such a register would have a positive predictive value, but not enough to be operationally effective. In addition it seems likely that the prediction of the children who were in fact predicted may have resulted in little practical benefit. Few would be diagnosed

TABLE II

Selective Power of Single Items Among 3,480 Births

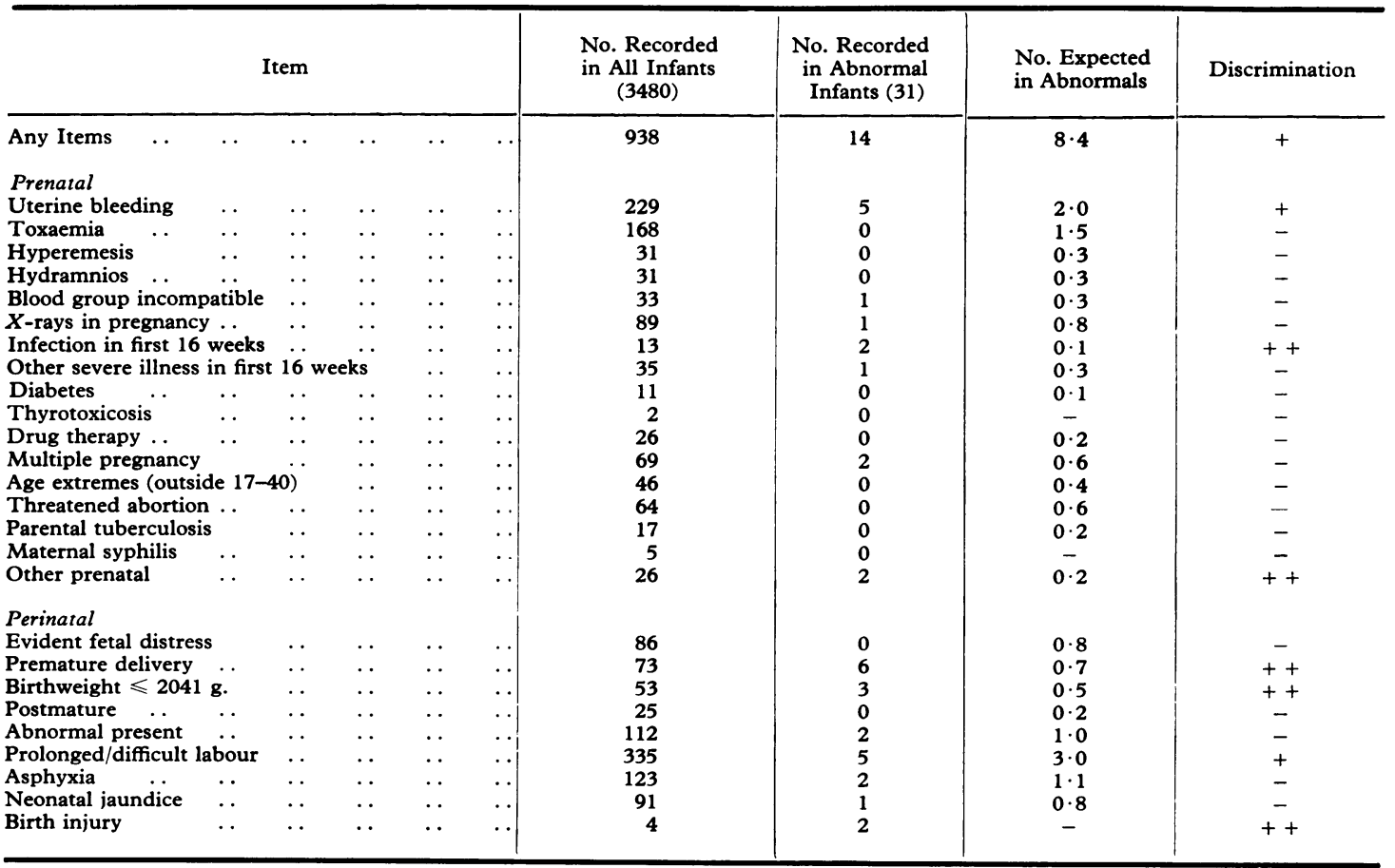

Premature delivery not exactly defined. Many recorded as nominal 36 weeks. Many no doubt are birthweights between $2041 \mathrm{~g}$. and $2493 \mathrm{~g}$. . rather than estimations of gestation length.

The 938 'any items' excludes those with evident handicap at birth and those who were registered retrospectively. 
more quickly than as the result of normal symptomatic presentation, and for most there was no effective treatment.

Table II lists the reasons for which children were entered in the Observation Register and the frequency with which these reasons occurred in the above 31 infants. Proportionate expected values are also given for the latter, and items of possible selective value are marked.

A more detailed analysis is carried out in Table III to see what particular combinations of the more selective items might prove the most effective, and it can be seen that selection on the basis of either premature delivery or a birthweight of less than or equal to 2041 g., specified 82 infants of whom 7 were in the abnormal (31) group. The addition to these criteria of birth injury, or maternal infection during the first 16 weeks of pregnancy, raised the number selected to 84 infants of whom 11 were in

TABLE III

Selective Power of Combinations of Most Powerful Single Items

\begin{tabular}{|c|c|c|c|}
\hline Item Combination & \begin{tabular}{|} 
No. Recorded \\
in All \\
Infants \\
$(3480)$
\end{tabular} & $\begin{array}{c}\text { No. Recorded } \\
\text { in } \\
\text { Abnormals } \\
(31)\end{array}$ & $\begin{array}{l}\text { No. Expected } \\
\text { in } \\
\text { Abnormals }\end{array}$ \\
\hline $\begin{array}{l}\text { A: Premature delivery } \\
\text { B: A + birthweight } \\
\leqslant 2041 \text { g. } \\
\text { C: B + infection in first } \\
\text { trimester, or birth } \\
\text { injury } \\
\text { D: C + other severe } \\
\text { illness in first } \\
\text { trimester } \\
\text { E: D + prolonged/ } \\
\text { difficult labour } \\
\text { F: E + uterine bleeding } \\
\text { G: any item }\end{array}$ & $\begin{array}{r}84 \\
\\
93 \\
295 \\
353 \\
922\end{array}$ & $\begin{array}{l}11 \\
12 \\
13 \\
13 \\
14\end{array}$ & $\begin{array}{l}0 \cdot 8 \\
2 \cdot 6 \\
3 \cdot 1 \\
8 \cdot 2\end{array}$ \\
\hline
\end{tabular}

the abnormal group. At this level an 'At Risk Register' would have been less than one-tenth of the size of the existing Observation Register and yet would have selected 11 of the 14 cases which were in fact selected. Indeed, extension of the criteria of selection beyond line 3 of Table III is rather worse than a random selection, and on the basis of this sample there are no grounds for doing so.

(B) Second analysis. 358 of the 652 records on the Education Handicap file (54.9\%) were successfully linked with existing birth records. The handicapped child file does not record the place of birth, so it was not possible to say certainly what proportion of unlinked handicaps were unlinked for technical reasons (e.g. errors of identification record), but a hand search of listed cases failed to identify any of them and it must be presumed that the majority were born elsewhere than Birmingham. Presumably an equivalent number of handicapped children born in Birmingham may have left the district, and these inward/outward exchanges must affect any quantitative interpretations placed upon our data.

For purposes of comparing handicap rates in different groups of children, we used as denominators the numbers of infants born alive, who had no malformation evident in the first year, who were still alive and known to be resident in the City at 5 years old, and who had full identity labels, including name-code and date of birth. This amounted to 12,477 infants from a total of 18,022 live births. Emigration from Birmingham is not specifically coded so there was no way of knowing how many had been excluded because of technical incompleteness of their records with respect to their presence at 5 years old. However, in numerical terms at least, the proportion selected for a suitable denominator is similar to the proportion of handicapped children successfully linked. To a first approximation the ratio of the one to the other may be taken as an estimate of the prevalence of handicap in particular groups.

The male/female ratios in linked and unlinked sets, $211 / 147$ for the former and $187 / 108$ for the latter, were not significantly different. Among the 358 linked cases, $11(3 \cdot 1 \%)$ had hearing defects, $17(4 \cdot 7 \%)$ had visual defects, $17(4 \cdot 7 \%)$ had cerebral-motor defects, $13(3.6 \%)$ were mentally defective for evidently physical reasons, 161 $(45 \cdot 0 \%)$ were educationally subnormal, $26(7 \cdot 3 \%)$ had congenital physical defects or genetic disorders, $82(22 \cdot 9 \%)$ had acquired disabilities, and $31(8 \cdot 6 \%)$ were otherwise or incompletely specified. The distribution among the unlinked cases was essentially similar except that the proportion of congenital physical disorders or genetic handicaps was somewhat less, $7 / 294(2 \cdot 4 \%)$.

Thirty of the 358 linked cases $(8 \cdot 4 \%)$ had handicaps which were or should have been evident at birth or very shortly afterwards, and they could not reasonably be registered as 'at risk'. Because they were not relevant to evaluating the operational effectiveness of prediction, subsequent analyses are limited to the remaining 328 linked cases with handicaps not evident at birth.

Sex. Males were more liable to handicap than females, 196 of $6378(3 \cdot 1 \%)$ compared with 132 of $6099(2 \cdot 2 \%)$. Most of this difference was due to the different proportions of educationally subnormal, $(1.6 \%)$ in the males and $0.8 \%$ in the females. 
Obstetric difficulties. A series of handicap rates is presented in Table IV according to the occurrence of various obstetrical abnormalities. There was a modest increase among infants having recognized birth injury and among those with abnormal obstetric presentations (mostly occipitoposteriors) or instrumental vaginal delivery, though the excess was statistically significant only for the last group.

\section{TABLE IV}

Handicap Rates (\%) After Obstetric Abnormalities

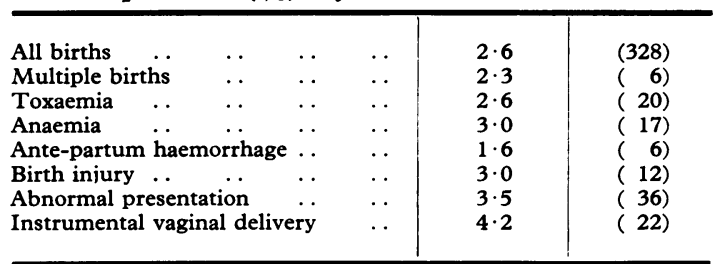

Absolute numbers of handicaps in parentheses in Tables IV-VIII

Immaturity. Birthweight and gestation are interrelated variables, and they are presented jointly in Table V. On biological grounds we may expect these relationships to be complex and the pattern of sickness in infants of low weight and normal gestation is probably different from that in infants of normal weight and short gestation. However, for simple prediction of any kind of handicap, the birthweight criterion seems to be more efficient than the gestation period so far as this sample is concerned, and provided that the birthweight was known, gestation added nothing sub-

TABLE V

Handicap Rate (\%) According to Gestation and Birthweight

\begin{tabular}{|c|c|c|c|c|c|}
\hline \multirow{2}{*}{\multicolumn{3}{|c|}{$\begin{array}{l}\text { Birthweight } \\
\text { (g.) }\end{array}$}} & \multicolumn{3}{|c|}{ Gestation (wk.) } \\
\hline & & & $\leqslant 35$ & $\leqslant 39$ & $\geqslant 40$ \\
\hline$\leqslant 2495$ & . & . & $5 \cdot 3(9)$ & $3 \cdot 6(13)$ & $7 \cdot 3(11)$ \\
\hline$\leqslant 3486$ & . & . & \multirow{2}{*}{$3 \cdot 2(4)$} & $3 \cdot 1(72)$ & $2 \cdot 3(86)$ \\
\hline$\leqslant 3515$ & . & $\ldots$ & & $2 \cdot 2(17)$ & $1 \cdot 8(51)$ \\
\hline
\end{tabular}

65 cases excluded because duration of gestation not stated.

TABLE VI

Handicap Rate (\%) According to Birthweight for all Gestations

\begin{tabular}{|c|c|c|c|c|}
\hline \multicolumn{5}{|c|}{ Birthweight (g.) } \\
\hline $\begin{array}{r}\leqslant 2239 \\
5 \cdot 2(15)\end{array}$ & $\begin{array}{l}\leqslant 2495 \\
4 \cdot 6(18)\end{array}$ & $\begin{array}{l}\leqslant 2976 \\
3 \cdot 0(66)\end{array}$ & $\begin{array}{l}\leqslant 3486 \\
2 \cdot 3(95)\end{array}$ & $\begin{array}{l}>3486 \\
2 \cdot 0(69)\end{array}$ \\
\hline
\end{tabular}

stantial in addition. Handicap rates according to birthweight are given in Table VI.

TABLE VII

Handicap rate (\%) According to Birth Rank and Maternal Age

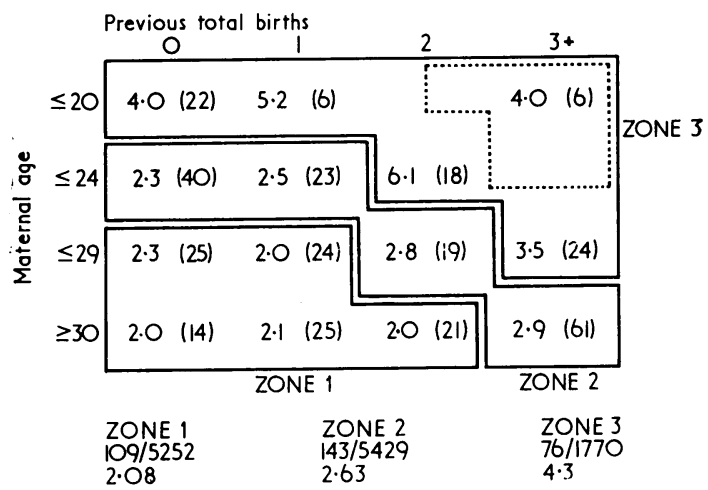

Birth rank and maternal age. Table VII presents handicap rates according to birth rank and maternal age. There is a falling proportion of handicap with increasing maternal age at each birth rank and a less regular pattern by previous total births at each maternal age. There is a suggestion that this pattern reflects that demonstrated for post-neonatal infant mortality where high birth rank in younger mothers has an adverse effect. The pattern suggests the operation of social determinants selected secondarily on the basis of frequent childbearing. A zonal analysis on this basis is presented at the foot of Table VII. We examined some more direct indices of social circumstances and classified children according to the general standard of housing in the electoral district in which they lived. We examined also the effect of duration of maternal work during pregnancy and of the ratio of persons per room in the house where the child lived. The various comparisons are presented in Table VIII and confirm in general the positive association between poor social circumstances and a relatively high risk of handicap.

Finally we explored to what extent it was possible

TABLE VIII

Handicap Rate (\%) According to Social Determinants

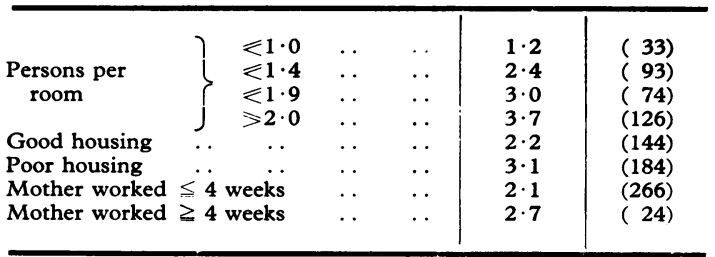


to predict handicap using various combinations of the most powerful of the predictors so far identified. The occurrence of instrumental delivery or abnormal delivery or abnormal presentation or birth injury or a combination, isolated $\mathbf{5 4}$ handicapped children among 1596 children so specified, a rate of $3.4 \%$. A combination of a poor housing area and crowding of 1.5 persons per room or worse isolated 120 handicapped children among 3401 , a rate of $3.5 \%$. Either of these two sets of criteria, or a birthweight less than or equal to 2495 g., or a maternal age/ birthweight combination in zone 3 of Table VII, or a birth rank of 5 or higher at any age, resulted in the isolation of 221 handicapped children among 6489 selected, $3 \cdot 2 \%$. The rate among the children unselected on these criteria was $1.8 \%$, about half that in the selected group. From an operational point of view, selection on this basis would involve $52.0 \%$ of children and they would contain $67.4 \%$ of all handicaps.

\section{Discussion}

The problems of evaluating the operational effectiveness of prediction from data not specifically designed or maintained for that purpose are sufficiently clear. The multiple purposes of the Observation Register were enough to prevent a reliable self-evaluation, and this must apply to all registers of similar design. Even with adequate design in this respect evaluation of longer term prediction is hindered by the migration problem as the second analysis showed. Though the proportion of successful linkages of handicapped children was of the same order as the proportion of ascertained follow-ups for all children, the deficiencies in both leave room for self-selection effects. The relatively high rate for linked handicap in poor social circumstances is almost certainly, in part, a function of relatively low mobility and it is impossible to say to what extent the findings are explained by it .

However, the effects of birthweight, short gestation, traumatic delivery, and the indices of social underprivilege are as might be expected, and as have in fact been shown in Birmingham for postneonatal infant mortality (Knox and Mackintosh, 1958) for severe neurological damage (Griffiths and Barrett, 1967), and for poor educational performance at ordinary primary schools (Barker and Edwards, 1967).
Despite the interest of these positive associations and their probable biological meaningfulness, the main conclusions with respect to operational usefulness are negative. None of these bases of prediction is sufficient to warrant the special concentration of surveillance resources upon, or particularly the withdrawal of surveillance froml any particular group. For purposes of operationa, guidance it is difficult to do better than quote from the analysis of Richards and Roberts (1967). 'The at risk concept is an unsound basis for the detection of handicapping disorders; there is no alternative to the clinical examination of all infants in the neonatal period, their screening for metabolic and auditory defects at the proper ages, and the careful observation of every infant's developmental progress by doctors, supported by health visitors.'

The only sensible action to be taken with respect to At Risk Registers is to abandon them. They do no good and possibly do harm.

This does not mean that existing observation registers are beyond redemption or that they are necessarily useless in respects other than prediction. It means that their tasks need to be more accurately defined and their methods adapted to the tasks. The need is to monitor all children and the tasks of the operational and data-handling systems are to assist the supervision of the known handicapped and to see that all young children, and not just some, are assessed as necessary to a defined plan.

Acknowledgements are due to the Association for the Aid of Crippled Children for financing data-processing costs for the Birmingham Maternity data, to the Nuffield Provincial Hospitals Trust for the computer facilities used for the definitive analysis, and to the City Education Department for access to information; also to Mrs. Karen Glenn for programming the linkage operations.

\section{REFERENCES}

Barker, D. J. P., and Edwards, J. H. (1967). Obstetric complications and school performance. British Medical fournal, 3, 695. Griffiths, M. I., and Barrett, N. M. (1967). Cerebral palsy in Birmingham. Developmental Medicine and Child Neurology, $9,33$.

Knox, G., and Mackintosh, J. (1958). Post-neonatal infant mortality in Birmingham between 1947 and 1956. British fournal of Preventive and Social Medicine, 12, 131.

Richards, I. D. G., and Roberts, C. J. (1967). The 'at risk' infant. Lancet, 2, 711.

Correspondence to Professor E. G. Knox, Department of Social Medicine, The Medical School, Edgbaston, Birmingham 15. 